Original Research Paper

\title{
Bacteria Contaminants and their Antibiotic Sensitivity from Selected Herbal Medicinal Products from Eldoret and Mombasa, Kenya
}

\author{
${ }^{1}$ Lucia Keter, ${ }^{2}$ Richard Too, ${ }^{1}$ Nicholas Mwikwabe, ${ }^{3}$ Stanley Ndwigah, \\ ${ }^{1}$ Jennifer Orwa, ${ }^{2}$ Elizabeth Mwamburi, ${ }^{1}$ Richard Korir and ${ }^{1,4}$ Charles Mutai \\ ${ }^{I}$ Kenya Medical Research Institute, Centre for Traditional Medicine and Drug Research, P.O. Box 54840-00200, Nairobi, Kenya \\ ${ }^{2}$ Department of Biological Sciences, University of Eldoret, P.O. Box 1125-30100, Eldoret, Kenya \\ ${ }^{3}$ Department of Pharmaceutical Chemistry, School of Pharmacy, University of Nairobi, P.O. Box 19676-00202, Nairobi, Kenya \\ ${ }^{4}$ Department of Medical Laboratory Sciences, School of Public Health, Biomedical Sciences and Technology, Masinde Muliro \\ University of Science and Technology, P.O. Box 190-50100, Kakamega, Kenya
}

Article history

Received: 07-25-2015

Revised: $18-10-2015$

Accepted: 13-01-2016

Correspondings Author: Lucia Keter

Kenya Medical Research Institute (KEMRI), Centre for

Traditional Medicine and Drug Research, P.O. Box 5484000200, Nairobi, Kenya

Tel: +254-20-2722541

Fax: 254-20-2720030

E-mail: 1keter@kemri.org

\begin{abstract}
Herbal products are used worldwide for the treatment and prevention of various diseases and currently represent a substantial proportion of the global drug market. However, these products have the potential of being contaminated by different microorganisms due to poor hygienic practices during handling, processing and packaging. The main aim of this study was to evaluate microbial quality of herbal products marketed to the general population in Eldoret and Mombasa, Kenya. The study employed an exploratory as well as laboratory based experimental design. The herbal products were purchased from the markets and transported to Kenya Medical Research Institute laboratories for processing and analysis. Microbial contaminants were determined according to Pharmacopoeias and World Health Organization standards. Microbial pathogens were isolated, identified and drug susceptibility test was done as per National Laboratory Standards Institute protocol. The herbal products were in-form of powders, liquids, tablets, oils and capsules. Bacterial contamination was observed in $90 \%$ of the total samples and those with $>1000 \times 10^{4} \mathrm{cfu} / \mathrm{gm}$ or $\mathrm{ml}$ was $20 \%$ for Eldoret and $46 \%$ for Mombasa samples. Analysis of variance showed that the rate of microbial contaminants for Eldoret and Mombasa samples had no significant association $(p=0.084)$. Bacteria belonging to seven genera were isolated and antibiotic susceptibility test showed that $13.2 \%$ of the bacteria isolates were resistant. Multidrug resistance was observed with Klebsiella pneumonia, Shigella sonnei, Serratia erwinia, Serratia liquefaciens and Proteus penneri. These findings imply that conditions during harvest or postharvest processing of herbal products were unsanitary. Proper handling and storage of herbs should be observed in order to reduce the amount of microbial contaminants. Only $16 \%$ of herbal product samples evaluated met the standards for microbial limits as specified in Pharmacopoeias. Thus, emphasis on improvement of plant material quality and establishing better hygienic conditions during production of herbal medicines is recommended.
\end{abstract}

Keywords: Herbal Products, Quality, Microbial Contaminants, Antimicrobial Resistance, Diseases

\section{Introduction}

Plant derived products are increasingly being sought out as medicinal products, nutraceuticals and cosmetics worldwide. In Sub-Saharan Africa and developing countries in general, herbal medicines are considered to be more readily accessible, affordable, culturally acceptable and sustainable than conventional 
medicines (UNAIDS and WHO, 2009; Patwardhan et al., 2005; Barnes, 2003). In developed countries, these products are also gaining popularity particularly due to lack of curative treatment for several chronic diseases, increased side effects of conventional medicines, high cost of new drugs, microbial resistance, emerging diseases and the growing evidence supporting the efficacy of some of the herbal products (Langlois-Klassen et al., 2007; Patwardhan et al., 2005; Barnes, 2003). According to WHO estimates, the present demand for medicinal plants is about USD 14 billion annually and it is projected that by the year 2050 it will be approximately USD 5 trillion (WHO, 2007). These products are available in supermarkets, health food shops and pharmacies as overthe-counter self-medication. Several authors have reported that $30-70 \%$ of HIV-infected persons worldwide use herbal products (UNAIDS and WHO, 2009; Liu et al., 2005; Harnack et al., 2001).

Kenya being a developing nation faces various socioeconomic problems such as poverty, illiteracy and diseases (KHSP, 2010). The high levels of communicable diseases coupled with poverty have forced many people to rely heavily on medicinal herbal products for their primary health care needs. However, the natural products subsector in Kenya has largely remained un-regulated by either an Act of Parliament or policy governing the production, quality and sale of herbal medicine and where the laws exist, they are either inadequate or, to a large extent, un-coordinated both in structural and regulatory terms. As a result, unsuspecting public have been exposed to high levels of disease causing microorganisms. Most consumers and vendors believe and consider herbal products to be safe but microbial contamination in medicinal herbs is a concern, especially among the immuno-compromised individuals as a result of their lowered immunity (Ernst, 1999). Medicinal herbs have been reported to be contaminated with microorganisms indigenous to the soil and plants where they are grown (Okunlola et al., 2007; Govender et al., 2006; Czech et al., 2001). Poor conditions during harvesting and post-harvest handling of the herbs and herbal products also predispose them to contamination (Farkas, 2000; Candlish et al., 2001). Studies have reported contamination of herbal products with disease causing organisms such as Bacillus sp., Enterobacteriaceae, Salmonella sp., Staphylococcus aureus (Govender et al., 2006). Additionally, elevated levels of coliforms and soil born bacteria contaminants have been observed in herbal drugs and spices (Candlish et al., 2001). The other challenge is the presence of "adulterants" which in actual sense mean intentional or unintentional presence of undeclared ingredients. This can have negative impact on the overall product in terms of safety, efficacy and quality. This adulteration may be due to toxicity of the added undisclosed ingredients as well as microorganisms together with their by-products such as bacterial toxins. The aim of the study was to evaluate microbiological quality of herbal products marketed to the general population in Eldoret and Mombasa towns of Kenya.

\section{Materials and Methods}

\section{Study Design}

The study employed an exploratory and laboratory based experimental design.

\section{Study Sites}

A survey of herbal products was carried out in the month of October 2012 in both Eldoret and Mombasa and their environs (Fig. 1). The two selected study sites enjoy different climatic conditions and cultural diversity. Eldoret is located in the highlands and Mombasa is found along the coastal strip of Kenya. Mombasa is the second-largest city in Kenya and the Country's chief port. The climate of Kenya varies by location and the climate along the coast is tropical. This means rainfall and temperatures are higher throughout the year. At the coastal city of Mombasa the air changes from cool to hot ( 21 to $33^{\circ} \mathrm{C}$ ), almost every day with relative humidity of 29 to $99 \%$. Eldoret town, on the other hand, is located in the Western part of the country. It is the capital and largest town in Uasin Gishu County and the $5^{\text {th }}$ largest urban centre countrywide. Eldoret elevation varies from about 2100 metres to more than 2700 metres above sea level. Both towns are highly cosmopolitan but majority of the population in Eldoret and its environs are the Kalenjins while in Mombasa, majority of the population are the Swahili and Mijikenda. The population was 252,061 in Eldoret and 915,101 in Mombasa in the 2009 census. Kenya has 42 tribes (KNBS, 2009) and each has peculiar customs and beliefs. Hence, the use of herbal medicine is equally different among the various communities in Kenya.

\section{Sample Collection}

Herbal products were purchased from herbal clinics, nutrition stores, herbal product manufacturers, local retailers and hawkers/street vendors in Eldoret and Mombasa towns. The liquid herbal products were collected and packaged in sanitary containers while the powdered products were packed in sanitary brown envelopes and transparent polyethylene bags and transported to the Kenya Medical Research Institute (KEMRI) laboratories for processing and analysis. The samples were assigned unique codes that were used in laboratory assays, data analysis, report writing and presentation of the results. The bacterial contamination assays were carried out at the Centre for Microbiology Research laboratories in KEMRI.

\section{Sample Size}

Due to the presence of many unregulated herbal products in the Kenyan markets with many different pharmacological claims, appropriate numbers of representative samples were purposively collected. Surveys into the quality of conventional drugs in the 
Kenyan market indicated a general failure rate of about $10-20 \%$. Based on this observation, the study estimated that approximately $15 \%$ of the herbal products do not meet the quality standards since the failure rate in the herbal products has not been documented. Therefore Fisher et al. (1998) formulae was used to determine the sample size:

$$
N=\frac{Z_{1-a}^{2}[P(1-P)]}{D^{2}}
$$

Where:

$\mathrm{N}=$ Sample

$\mathrm{Z}=$ Standard error from the mean at 1.96

$\mathrm{P}=$ Prevalence $(\%$ rate of quality failure $)$

$\mathrm{D}=$ Absolute precision (at $5 \%$ ), $\mathrm{a}=$ level of significance (at 5\%)

Hence:

$$
N=\frac{1-96_{1-0.5}^{2}[0.15(1-0.15)]}{0.05^{2}}
$$

$\mathrm{N}=100$; minimum of 100 herbal products were purposively sampled for the study where 50 samples were each collected from Eldoret and Mombasa towns.

\section{Determination of Microbial Contamination}

Microbial contaminations were determined according to Pharmacopoeias and WHO requirements (EP, 2007; WHO, 2007; USP, 2005). Microbiological parameters considered in this study were total bacteria viable content and their number in terms of Colony Forming Units (CFU). One (1) gm of each herbal product in powder, tablet and capsule form were aseptically suspended in $1 \mathrm{~mL}$ of either hot or cold sterile distilled water (as per the label claim preparation instructions), mixed thoroughly and filtered before serial dilutions were done. Appropriate serial dilutions were made and $0.1 \mathrm{~mL}$ of the dilution transferred aseptically to sterile Petri dish containing culture media; the samples were cultured in different media supporting bacterial growth. The media used were general purpose media, selective, differential and enrichment media. Double plates of each sample were incubated at $37 \pm 2{ }^{\circ} \mathrm{C}$ for $12-16 \mathrm{~h}$. After incubation, CFU were determined, distinct colonies were subcultured. For the liquid/oils formulations, $1 \mathrm{~mL}$ was taken then serial dilution carried out accordingly. The samples were transferred into the culture media and incubated as outlined above. Bacteria isolates were presumptively identified using Gram stain reagents and biochemical tests (WHO, 2007; Abba et al., 2008).

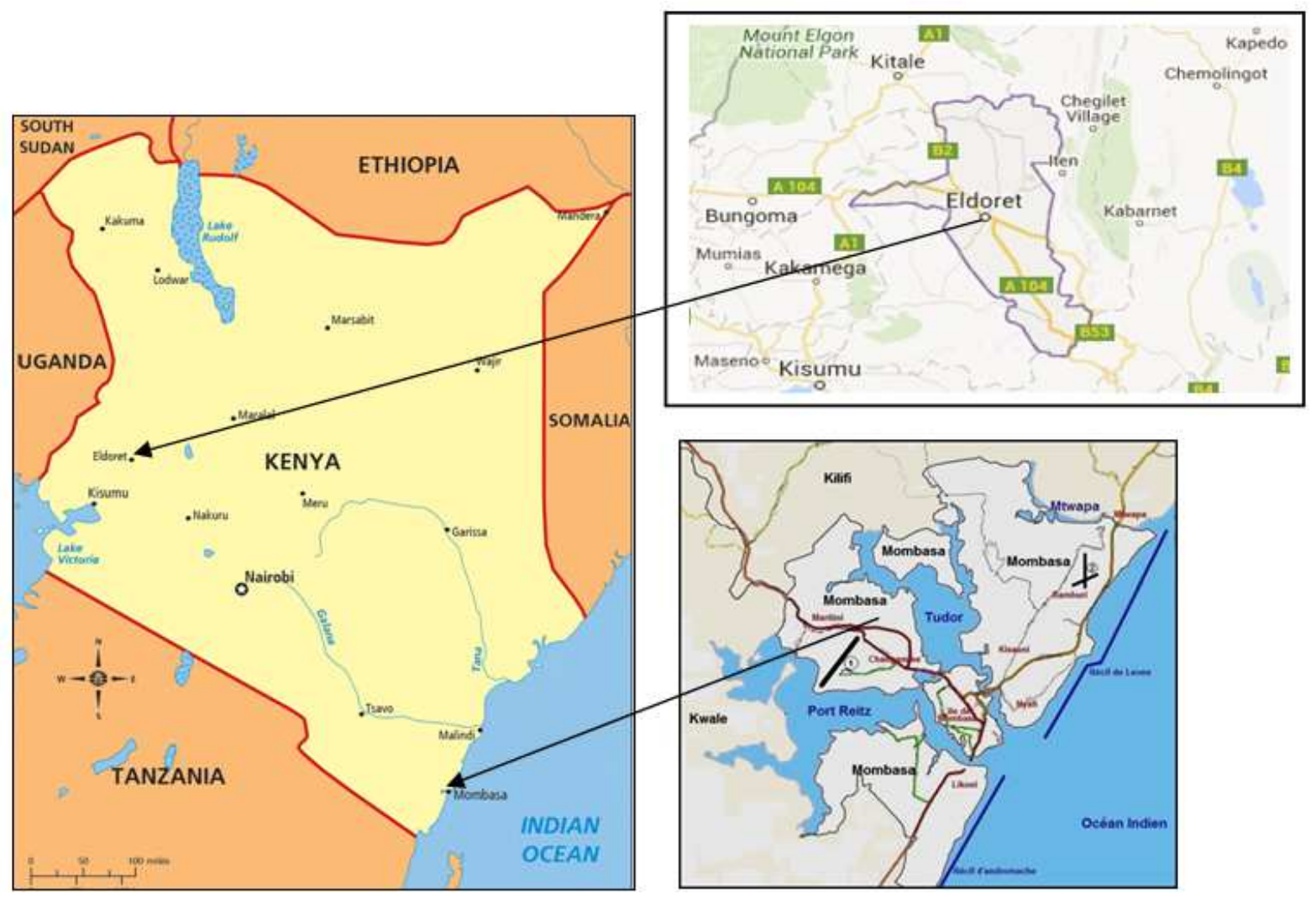

Fig. 1. A map of Kenya showing the location of the study sites 


\section{Identification of the Isolated Bacteria}

Samples positive for bacteria were sub-cultured onto Mueller Hinton agar to obtain pure colonies. Pure cultures were used for identification using biochemical techniques. Gram reactions were done to classify bacteria as gram positive and gram negative. Biochemical reactions such as indole, motility, citrate and urease were used to identify the isolated bacteria up to the species level. The pure isolates were sub-cultured on nutrient agar and inoculated onto the biochemical media. The inoculated media were incubated for $12-16 \mathrm{~h}$ at $37^{\circ} \mathrm{C}$. After incubation biochemical reactions were then read and interpreted against a standard chart (NLSI, 2006). Confirmations of the isolates were done using API Staph and API 20 E strips/media.

\section{Disk Diffusion Method for Antibiotic Susceptibility Test}

Antibiotic susceptibility test was performed using disc diffusion method (Kirby et al., 1966). The study used commercially prepared antibiotics disks containing piperacillin PRL, ciprofloxacin CIP, norfloxacin NOR, cefotaxime CTX, gentamicin $\mathrm{CN}$, sulphamethoxazole/trimethoprim SXT, cefepime FEP and ceftazidime CAZ. Briefly, from a freshly growing pure colony of the test bacteria, a $0.5 \mathrm{McF}$ arland suspension was prepared and spread uniformly on the surface of Mueller Hinton agar to give standard concentration (approximately $1-2 \times 10^{8} \mathrm{CFU} / \mathrm{mL}$, a 0.5 McFarland). Commercially prepared disks; each of which pre-impregnated with a standard known concentration of the test antibiotic, were aseptically pressed lightly onto the centre of agar surface. The test antibiotic immediately diffused outward from the disks, creating a gradient of antibiotic concentration in the agar such that the highest concentration was found close to the disk with decreasing concentrations further away from the disk. After an overnight incubation, the bacterial growth around each disc was observed. If the test isolate was susceptible to a particular antibiotic, a clear area of "no growth" was observed around that particular disk (NLSI, 2006).

The zone around an antibiotic disk that had no growth also referred to as the zone of inhibition approximated the minimum antibiotic concentration sufficient to prevent growth of the test isolate. This zone was measured in millimetres and compared to a standard interpretation chart used to categorize the isolate as sensitive, intermediate or resistant (NLSI, 2006).

\section{Statistical Analysis}

Bacterial counts were transformed to common logarithmic values for statistical analysis. The SPSS (version 20) software was used for analysis. The microbial contamination data was analysed statistically using ANOVA and results compared with the Pharmacopoeias and WHO requirements (EP, 2007; WHO, 2007; USP, 2005). The total microbial count was determined and compared with the recommended limits. The $\mathrm{p}$-value $\leq 0.05$ was considered significant. The degree of variability of bacteria was evaluated and tabulated.

\section{Ethical Considerations}

The study approval was granted by Kenya Medical Research Institute Scientific Steering Committee and Ethical Review Committee (SSC No. 2300). Before purchasing of the herbal products samples, the objective of the study was explained to the hawkers/street vendors and the THPs and were assured that confidentiality would be maintained throughout the study. The samples were then coded and these codes were used in laboratory assays, data analysis and report writing. The codes consisted of a site identifier, ELD for Eldoret samples and MSA for Mombasa samples, followed by a number indicating the sequential order of the sample.

\section{Results}

\section{The Level of Bacterial Contamination}

One hundred herbal products (50 from Eldoret and 50 from Mombasa) collected by purposive sampling were analysed for bacteria contaminants. The herbal products were in different formulations and were packaged in various packages. The formulations were $15 \%$ tablets, $1 \%$ capsules, $26 \%$ liquids (different concoctions and decoctions), $5 \%$ oils and $53 \%$ powders that where either packed in the original pack or dispensed into bottles or paper bags. The herbal samples from Eldoret were 34/50 powders, $14 / 50$ were liquids and 2/50 of the samples were oils while for Mombasa, 19/50 were powders, $12 / 50$ were liquids, $1 / 50$ in capsule form, $15 / 50$ were in tablets form and $3 / 50$ were in oils form.

The bacterial CFU were determined for both Eldoret and Mombasa samples. The CFU ranged from 0 to $>1000$. Zero (0) indicate that the samples had no contaminants while $>1000$ indicates that the samples were highly contaminated. After 12-16 h of incubation, the levels of contamination as expressed in CFU in total were as follows; $10 \%(10 / 100)$ of the samples were clean without any bacterial growth, 33/100 (33\%) had as high as $>1000 \times 10^{4} \mathrm{CFU} / \mathrm{gm}$ or $\mathrm{CFU} / \mathrm{ml}$. Eldoret had $10 / 50$ $(20 \%)$ samples with $>1000 \times 10^{4} \mathrm{CFU} / \mathrm{gm}$ or $\mathrm{ml}$ and $23 / 50$ $(46 \%)$ of the Mombasa samples had $>1000 \times 10^{4} \mathrm{CFU} / \mathrm{gm}$ or ml. Thirty-three (33) out of 34 (97\%) powders, 9/14 $(64.3 \%)$ liquids (concoctions and decoctions) and $1 / 2$ $(50 \%)$ of the oils from Eldoret were contaminated while the two conventional drugs included as controls (Control 1 and Control 2, chlorphenamine and paracetamol syrups, respectively) had no contamination $(\mathrm{CFU}=0)$. The mean bacteria $\mathrm{CFU}$ in liquid formulations were $324.14 \times 10^{4}, \quad 201.00 \times 10^{4}$ in oil formulation and $467.00 \times 10^{4}$ in powder formulation from Eldoret. In 
Mombasa, tablets and capsules were also sampled. Bacterial contaminations were high in liquids and tablets followed by powders and oils in that order. Eighteen (18) out of $19(94.7 \%)$ powders, $12 / 12(100 \%)$ liquids (concoctions and decoctions), 15/15 (100\%) tablets and $1 / 3(33.3 \%)$ of the oils were contaminated. The mean bacteria CFU in capsule formulation was $1000.00 \times 10^{4}$, $514.25 \times 10^{4}$ in liquid formulations, $596.43 \times 10^{4}$ in powders and $437.08 \times 10^{4}$ in tablets formulation from Mombasa. The p-values showed that there were no significant association $(\mathrm{p}=0.084)$ between
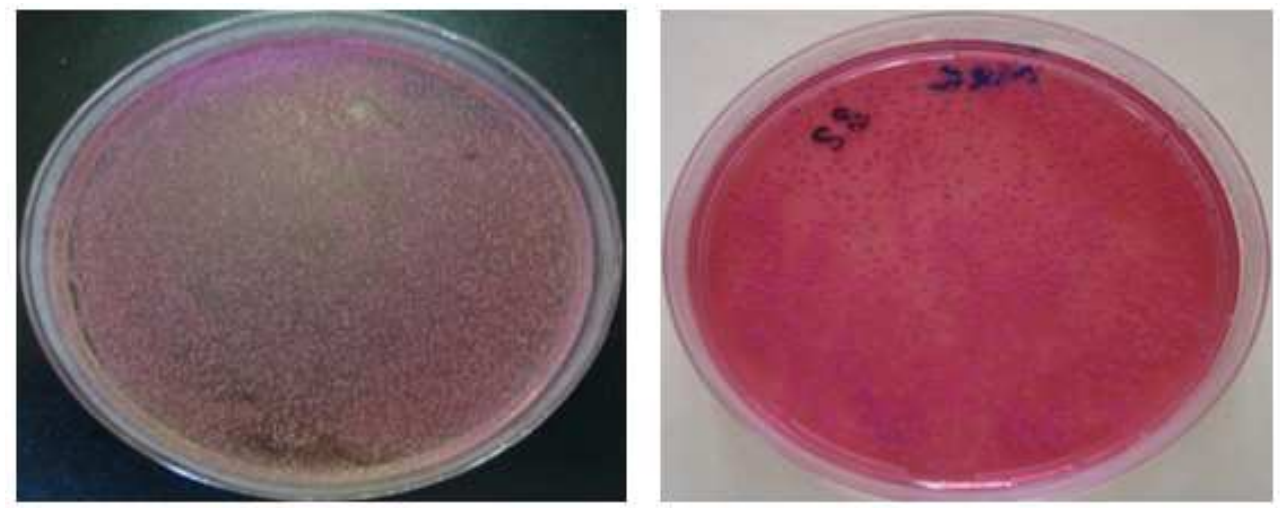

Fig. 2. Bacterial colony forming units of a sampled herbal product
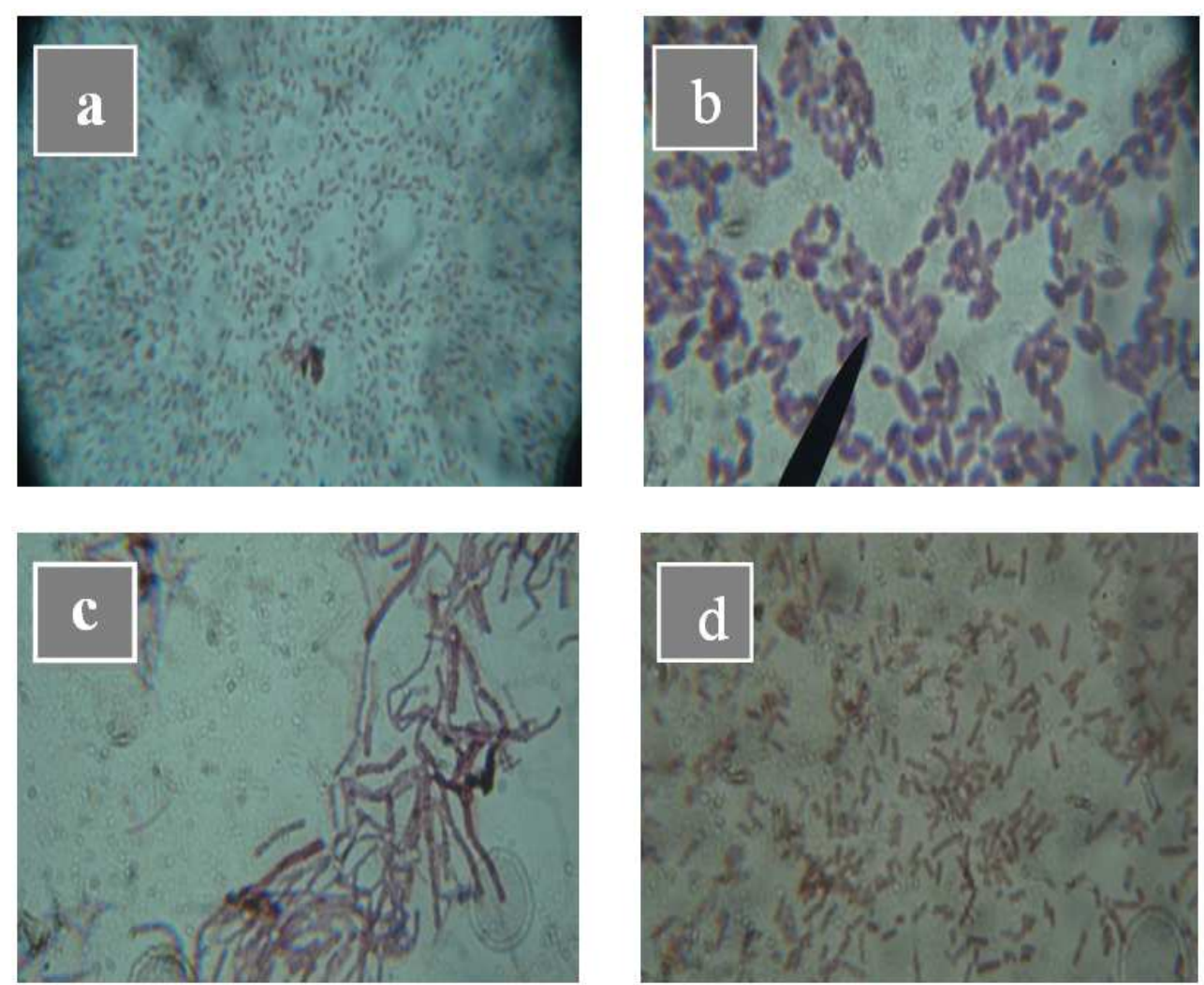

Fig. 3.Gram negative slides of some of the isolated bacteria a Gram negative cocci, b Gram negative large rods, c. Gram negative short rods and d. Gram negative normal rods 

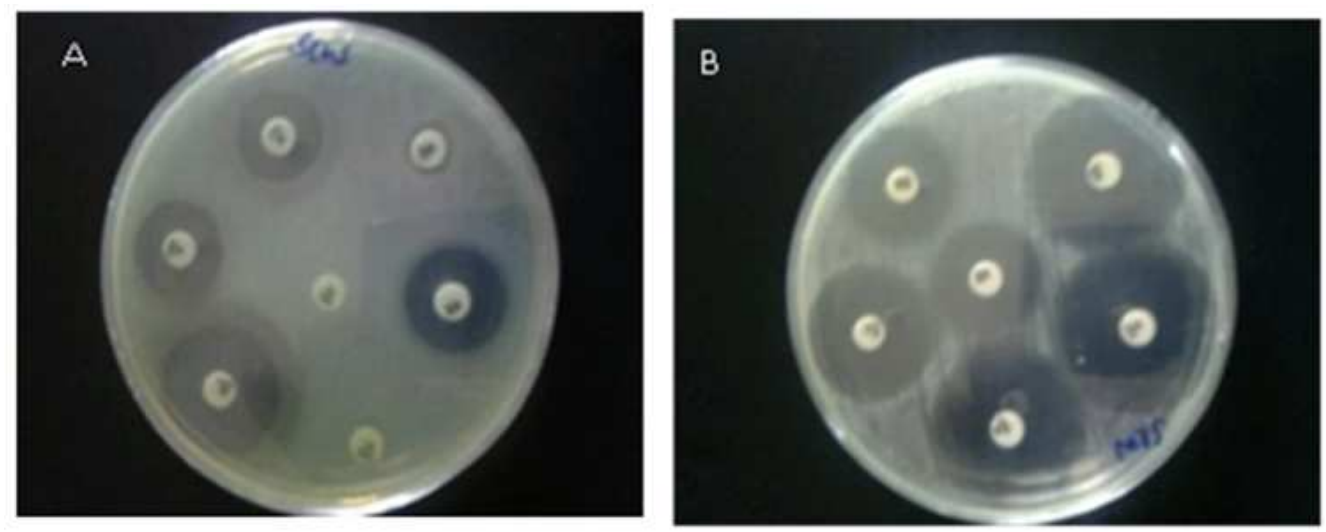

Fig. 4. Drug susceptibility test of some selected bacteria isolated from Eldoret and Mombasa samples

Table 1. Bacteria colony forming units for the Mombasa and Eldoret herbal products

\begin{tabular}{|c|c|c|c|c|c|c|c|c|c|}
\hline Site & $\begin{array}{l}\text { Formulation } \\
\text { form }\end{array}$ & $\begin{array}{l}\text { Mean } \\
\text { CFU }\left(\times 10^{4}\right)\end{array}$ & $\mathrm{N}$ & Std. deviation & $\begin{array}{l}\text { Min } \\
\left(\times 10^{4}\right)\end{array}$ & $\begin{array}{l}\operatorname{Max} \\
\left(\times 10^{4}\right)\end{array}$ & $\begin{array}{l}\text { Range } \\
\left(\times 10^{4}\right)\end{array}$ & $\begin{array}{l}\text { Median } \\
\left(\times 10^{4}\right)\end{array}$ & $\mathrm{p}$-value \\
\hline \multirow[t]{3}{*}{ Eldoret } & Liquid & 324.14 & 14 & 394.812 & 0 & 1000 & 1000 & 223.5 & 0.084 \\
\hline & Oil & 201.00 & 2 & 284.257 & 0 & 402 & 402 & 201.0 & \\
\hline & Powder & 467.00 & 34 & 364.978 & 0 & 1024 & 1024 & 360.0 & \\
\hline \multirow[t]{5}{*}{ Mombasa } & Capsules & 1000.00 & 1 & 0.000 & 1000 & 1000 & 0 & 1000.0 & \\
\hline & Liquid & 514.25 & 12 & 520.158 & 0 & 1000 & 1000 & 548.5 & \\
\hline & Oil & 201.00 & 3 & 284.257 & 0 & 402 & 402 & 201.0 & \\
\hline & Powder & 596.43 & 19 & 433.193 & 0 & 1000 & 1000 & 860.0 & \\
\hline & Tablets & 437.08 & 15 & 476.083 & 0 & 1000 & 1000 & 152.0 & \\
\hline \multirow[t]{5}{*}{ Total } & Capsules & 1000.00 & 1 & 0.000 & 1000 & 1000 & 0 & 1000.0 & \\
\hline & Liquid & 393.27 & 26 & 442.091 & 0 & 1000 & 1000 & 223.5 & \\
\hline & Oil & 201.00 & 5 & 284.257 & 0 & 402 & 402 & 201.0 & \\
\hline & Powder & 525.45 & 53 & 399.176 & 0 & 1024 & 1024 & 395.0 & \\
\hline & Tablets & 437.08 & 15 & 476.083 & 0 & 1000 & 1000 & 152.0 & \\
\hline
\end{tabular}

*Min-Minimum contamination per formulation, Max-Maximum contamination per formulation, N- Samples number per formulation, $\mathrm{CFU} / \mathrm{ml}$ or $\mathrm{CFU} / \mathrm{gm}$

\section{Identification of Bacterial Isolates}

Presumptive identification of bacteria indicated that majority of the samples from the two regions were contaminated with bacteria from the environment and especially from soil. Identification was successful in many organisms although a few were identified up to genus level. The results showed that majority $(90 \%)$ of the bacteria isolated were gram negatives. Figure 3 shows some of the gram negative bacteria that were isolated.

Streptomyces sp and Bacillus anthracoides were the main bacteria isolated from most of the samples while Klebsiella pneumoniae was isolated from 12 out of the 100 samples (12\%); 6 samples from Eldoret and 6 from Mombasa. Shigella sonnei were isolated from $8 \%(4 / 50)$ samples from Eldoret and 6\% (3/50) samples from Mombasa while Escherichia coli were isolated from only 1 (2\%) sample (ELD 13) from Eldoret. The other important genera isolated were
Citrobacter sp., Enterobacter sp., Serratia sp. and Streptomyces sp. Table 2 show the frequency of the genera's of the isolated bacteria from the two study sites per formulation of the herbal products.

\section{Antibiotic Susceptibility Test}

The bacterial isolates tested for antibiotic susceptibility were from the following genera; Serratia (25), Enterobacter (37), Klebsiella (17), Shigella (13), Proteus (10), Escherichia (1) and Citrobacter (3) (Table 3).

Figure 4 shows some of the results for antibiotic susceptibility test. Majority (59.4\%) of the isolates were susceptible to the antibiotics tested with inhibition zone diameters of 15 millimetres and above. Resistance was observed in $13.2 \%$ of the isolates (Table 4) while intermediate resistance was $27.4 \%$. All the bacteria isolates were susceptible to PRL except Serratia erwinia and Proteus penneri that were resistant. Serratia erwinia was also resistant to CIP while all the other isolates were susceptible. 
Table 2. The spectrum of bacteria isolated from Eldoret and Mombasa herbal products

\begin{tabular}{|c|c|c|c|}
\hline \multirow[b]{2}{*}{ Formulations } & \multirow[b]{2}{*}{$\begin{array}{l}\text { Bacterial } \\
\text { genus }\end{array}$} & \multicolumn{2}{|c|}{ Number of bacteria per genus } \\
\hline & & $\begin{array}{l}\text { (Eldoret } \\
\text { samples) }\end{array}$ & $\begin{array}{l}\text { (Mombasa } \\
\text { samples) }\end{array}$ \\
\hline \multirow[t]{8}{*}{ Liquids } & Bacillus & 6 & 2 \\
\hline & Enterobacter & 1 & 1 \\
\hline & Klebsiella & 1 & 1 \\
\hline & Serratia & 1 & 2 \\
\hline & Streptomyces & 6 & 8 \\
\hline & Proteus & 0 & 3 \\
\hline & Shigella & 0 & 2 \\
\hline & Citrobacter & 0 & 1 \\
\hline \multirow[t]{8}{*}{ Powder } & Bacillus & 9 & 2 \\
\hline & Enterobacter & 11 & 5 \\
\hline & Klebsiella & 7 & 2 \\
\hline & Serratia & 13 & 3 \\
\hline & Streptomyces & 11 & 17 \\
\hline & Proteus & 2 & 9 \\
\hline & Shigella & 4 & 0 \\
\hline & Citrobacter & 2 & 1 \\
\hline \multirow[t]{8}{*}{ Oil } & Bacillus & 0 & 0 \\
\hline & Enterobacter & 1 & 0 \\
\hline & Klebsiella & 0 & 0 \\
\hline & Serratia & 0 & 0 \\
\hline & Streptomyces & 1 & 1 \\
\hline & Proteus & 0 & 0 \\
\hline & Shigella & 0 & 0 \\
\hline & Citrobacter & 0 & 0 \\
\hline \multirow[t]{8}{*}{ Tablets } & Bacillus & 0 & 3 \\
\hline & Enterobacter & 0 & 1 \\
\hline & Klebsiella & 0 & 3 \\
\hline & Serratia & 0 & 2 \\
\hline & Streptomyces & 0 & 11 \\
\hline & Proteus & 0 & 2 \\
\hline & Shigella & 0 & 2 \\
\hline & Citrobacter & 0 & 0 \\
\hline \multirow[t]{8}{*}{ Capsules } & Bacillus & 0 & 0 \\
\hline & Enterobacter & 0 & 0 \\
\hline & Klebsiella & 0 & 1 \\
\hline & Serratia & 0 & 1 \\
\hline & Streptomyces & 0 & 1 \\
\hline & Proteus & 0 & 1 \\
\hline & Shigella & 0 & 0 \\
\hline & Citrobacter & 0 & 0 \\
\hline Control 1 & & 0 & 0 \\
\hline Control 2 & & 0 & 0 \\
\hline
\end{tabular}

Control 1-Chlorphenamine; Control 2-Paracetamol

Serratia erwinia, Klebsiella pneumoniaee, Shigella sonei and Serratia liquefacien were resistant to NOR while Serratia erwinia, S. liquefaciens, Proteus penneri, Shigella sonnei and Klebssiela pneumoniae were resistant to CTX with the other isolates were sensitive. Serratia erwinia and $K$. pneumoniae were resistant to both CN and FEP while S. liquefaciens, Enterobacter intermedius and proteus sp. were resistant to FEP antibiotics. Serratia erwinia, Serratia liquefacien, $P$. penneri and $S$. sonei were resistant to CAZ.
Table 3. Number of bacteria isolates subjected to antibiotic susceptibility test

\begin{tabular}{lcc}
\hline Bacterial genera isolates & Frequency & Percent \\
\hline Serratia & 25 & 23.6 \\
Enterobacter & 37 & 34.9 \\
Klebsiella & 17 & 16.0 \\
Shigella & 13 & 12.3 \\
Proteus & 10 & 9.4 \\
Escherichia & 1 & 0.9 \\
Citrobacter & 3 & 2.8 \\
Total & 106 & 100.0 \\
\hline
\end{tabular}

Table 4. Resistance pattern of the bacteria isolates against the antibiotics

\begin{tabular}{ll}
\hline Bacteria isolates & Antibiotic resistant observed \\
\hline Serratia Erwinia (SE1) & CIP, PRL, CN, NOR, \\
& CAZ, SXT, CTX, FEP \\
Serratia Liquefaciens (SL9) & NOR, CTX \\
Proteus Penneri (PP4) & PRL, CAZ, SXT, CTX \\
Proteus sp.(PP1) & FEP \\
Shigella Sonnei (SS9) & NOR \\
Klebsiella Pneumonia (KP10) & NOR, SXT, CTX \\
Shigella Sonnei (SS10) & CAZ, CTX \\
Klebsiella Pneumonia (KP1) & CN \\
Klessiella Pneumonia (KP12) & FEP \\
Escherichia Coli (EC1) & SXT \\
Serratia Liquefaciens (SL7) & CAZ, FEP \\
Enterobacter Intermedius (EI14) & FEP \\
Serratia Liquefaciens (SL5) & FEP \\
Klebsiella Pneumonia (KP7) & FEP \\
\hline
\end{tabular}

\section{Resistant Patterns of the Bacteria}

Multidrug Resistance (MDR) was observed in some of the isolates. Resistance to only one antibiotic was noted with Shigella Sonnei (SS9) which was resistant to NOR, Klebsiella Pneumonia (KP1) was resistant to $\mathrm{CN}$, Escherichia coli (EC1) was resistant to SXT while Klessiella Pneumonia (KP12), Klebsiella Pneumonia (KP7), Serratia Liquefaciens (SL5), Enterobacter Intermedius (EI14) and Proteus species (PP1) were resistant to FEP. Serratia Erwinia (SEI) showed resistance to all the eight antibiotics tested while the rest of the isolates were resistant to 2 , 3 or 4 of the antibiotics tested (Table 4).

PRL-Piperacillin, CIP-Ciprofloxacin, NORNorfloxacin, CTX-Cefotaxime, CN-Gentamicin, SXTSulphamethoxazole/trimethoprim, FEP-Cefepime and CAZ-Ceftazidime.

\section{Discussion}

The numbers of Traditional Health Practitioners (THPs) in Kenya have increased in the last two decades (WHO, 2007). The THPs sampled in this study claimed that they could treat a wide range of illnesses such as malaria, typhoid, amoebiasis, high blood pressure, blood toxins, colon toxins, pneumonia, kidney disease, 
allergies, heart infections, sexually transmitted diseases, epilepsy, cancer, diabetes, arthritis, sterility, impotence, wound infections, skin infection, urinary tract infections and HIV among others. Abba et al. (2008) in their study on herbal products in Kaduma reported that the THPs claim to treat similar diseases and conditions as observed in this study. Although some of the hawkers/street vendors were generous in sharing the knowledge on the plants they use to prepare their products, most of the THPs were not willing to reveal the plants used to prepare their products. Packed and labelled herbal products from these THPs had insufficient information on the medicinal plants used to formulate the product. This is in agreement with other studies that have found that herbal products labels often cannot be trusted to reveal what is in the container (Kunle et al., 2012).

The main packaging material among the hawkers/street vendors was nylon paper bags and previously used plastic containers. These packaging materials could predispose the herbal products to contaminations. Kaume et al. (2012), in their study on microbial contamination of herbs marketed to HIVinfected people in Nairobi, reported similar packaging containers of herbal products in their study. The use of bottles and plastic containers previously used for other product could make the products susceptible to microbial or chemical contamination due to inadequate cleaning.

The study found that $90 \%$ of the total samples were contaminated with $33 \%$ having contamination $>1000 \times 10^{4} \mathrm{CFU} / \mathrm{gm}$ or $\mathrm{ml}$. Seventy percent of the $33 \%$ were from Mombasa and only 30\% from Eldoret. For samples free from contamination, the ones from Eldoret were more than twice those of Mombasa. Liquid samples from Mombasa were more contaminated than those from Eldoret while herbal powders were equally contaminated. Conventional drugs are prepared to meet good manufacturing practices unlike herbal preparations that are not governed by any legislative regulations. From the results, it was observed that the Mombasa samples were more contaminated than the Eldoret samples. This may be attributed to the fact that Mombasa is located at the coastal area of Kenya where relative humidity is high hence conducive for bacteria growth compared to weather conditions found in Eldoret (Rugut et al., 2010). Contamination may result from several sources, including improper cleaning procedures and open airdrying of plant materials resulting in contamination with soils and dust from the environment. Other sources of contamination could be unsterile water used for making liquids concoctions, handling the products with contaminated hands, using contaminated packaging materials, storage of herbal products passed their expiry dates among others. In addition, most of the herbal products are made from root barks and stem barks that are already in contact with the soil. Studies have shown that the presence of microbial contaminant in non-sterile pharmaceutical products can reduce or even inactivate the therapeutic activities of the product and has potential to adversely affect the patient taking the medication (Nakajima et al., 2005).

Some infectious disease outbreaks have been associated with the use of heavily contaminated raw materials of natural origin (Lau et al., 2003). Since the microbial quality of the Herbal Medicinal Products (HMP) is influenced by the environment and quality of the raw materials used during formulation, the manufacturers should ensure that the microbial load is brought to a minimal safety level. This should be done in the raw materials, finished dosage forms and the packaging components, to maintain appropriate quality, safety and efficacy of the products. The oils samples were noted to have the least contamination and from studies, essential oils have been known to have antimicrobial properties (Nakajima et al., 2005). Mean bacterial contamination for Eldoret was $<500 \times 10^{4}$ $\mathrm{CFU} / \mathrm{gm}$ or $\mathrm{ml}$ while that of Mombasa was $>500 \times 10^{4}$ $\mathrm{CFU} / \mathrm{gm}$ or $\mathrm{ml}$. This shows that contamination rate for Mombasa samples were high compared to Eldoret samples. However, the difference in the sample contamination was not significant $(\mathrm{p}=0.084)$. The limits of bacterial contamination according to the WHO and the European Pharmacopoeia for total aerobic bacteria is $10^{7} \mathrm{CFU} / \mathrm{g}$ or $\mathrm{ml}$ for herbal products to which boiling water is added before use and $10^{5} \mathrm{CFU} / \mathrm{g}$ or $\mathrm{ml}$ for those which boiling water is not added before use (WHO, 2007; EP, 2007). Most of the herbal products $(84 \%)$ in this study did not meet these specifications and similar findings have been reported (Abba et al., 2008; Okunlola et al., 2007).

Microbial count is just one of medicinal herb and products quality indicators. As per the pharmacopoeias as well as the WHO guidelines, all products must be free of true bacteria pathogens such as Salmonella spp. and E. coli (WHO, 2007; EP, 2007). In this study, soil bacteria formed the bulk of the isolates from samples of the two study sites. The two genera of bacteria, Streptomyces sp. and Bacillus sp. were isolated from $64 \%$ of the total samples. Bacteria that are of public health importance such as Bacillus species were isolated from the herbal products. The presence of Bacillus species may be as a result of inadequate heat processing, improper handling of products and contaminated processing equipment (Frazier and Westhoff, 2003). Of concern was the level of contamination by pathogenic gram negative bacteria such as Klebsiella pneumoniae (12\%), Shigella sonnei (7\%) and Escherichia coli (1\%). Other important genera of bacteria were Citrobacter sp., Enterobater sp. and Serratia sp. Although these bacteria 
are pathogenic, the herbalist claimed to treat all people including small children and HIV/AIDS patients. These bacteria could further endanger lives of immune compromised patients such as the HIV/AIDS, diabetics and children below 5 years of age. Coliforms such as $E$. coli are the most reliable indicators of faecal contamination, thus the test for their presence is an index of the degree of faecal contamination (Czech et al., 2001), which may indicate a possible presence of harmful disease causing organisms. Because heat treatment of herbal products results in a considerable reduction in the viable counts of $E$. coli, consumer education is critical to prevent foodborne illnesses. The significance of faecal bacteria is that if these specific bacteria are present then other harmful microorganisms may also be present, such as Salmonella (Forest, 2004). Pathogenic Gram negative bacteria such as Shigella sp. and $E$. coli that are expected to be absent were positive indications of the risks posed by the use of herbal preparations. Therefore, the high recovery rates of these suspected infectious bacteria from indigenous orally consumed herbal medications could be of clinical relevance (Shukla et al., 2004). Abba et al. (2008) in their study on herbal preparations found almost similar results. However, in contrast they isolated Staphyloccocus aureus and Salmonella typhi that were not isolated in the present study. The presence of large numbers of selected pathogenic bacteria in the analysed herbal medicinal preparations may be due to the methods of their preparation or the equipment and materials used in preparing and handling the herbal medicines. Some herbalists were selling their products by the road side thus exposure to dust was a possible source of contaminations. Other possible sources of contaminants are the personnel who may introduce the bacteria when handling the raw materials during processing. Therefore, the process of harvesting, drying, storage, handling and the soil influence the bacteriological quality of raw material which in turns affects the entire quality of the herbal preparation and the final finished products (Wylie and Nowicki, 2005). Manufacturers should ensure highest possible level of hygiene during manufacturing as well as the lowest possible level of pathogenic organisms in their herbal products so as to maintain correct quality, safety and efficacy of the final herbal preparations. Taking into consideration the above facts and increased use of herbal drugs in the society, poor quality control measures taken by the manufactures and vendors leave a great question mark on the safety to consumers' health (Deshpande et al., 2010). One of the major shortcomings of herbal preparations in developing countries including Kenya is the condition under which they are produced. These conditions are most often than not generally poor and unhygienic.
The isolates that were susceptible to the antibiotics tested in this study was lower (59.4\%) in comparison to a study by Alwakeel (2008) on microbial contaminants of herbal medicine who found that most $(75 \%)$ of the bacteria isolated were sensitive to the antibiotics. The ability of bacteria to evolve mechanisms to resist attack by antimicrobials (Angulo et al., 2004) was recognized soon after the widespread deployment of the first antibiotics. Resistance is an inevitable consequence of antibiotic use; the more they are used, the more bacteria will develop resistance (DeWaal et al., 2013).

In this study evidence of emerging multidrug resistant strains of bacteria was observed. Serratia erwinia (SE1) was found to be resistant to all the eight tested antibiotics while Proteus penneri (PP4) was resistant to 4 antibiotics. Klebsiella Pneumoniae (KP10) was resistant 3 antibiotics while S. Liquefaciens (SL9), S. Liquefaciens (SL7) and S. Sonnei (SS10) were each resistant to 2 antibiotics tested. The antibiotic Ciproflaxocine could be effective to all the strains that were resistant to $1,2,3$ or 4 antibiotics in this study. Only Serratia erwinia was resistant to all eight antibiotics tested. The Herbal Medicinal Products (HMPs) under investigation are dispensed to the already sick people hence can be of grave consequence bearing in mind the multidrug resistant bacteria contaminating the herbal products. Infections caused by resistant microorganisms often fail to respond to the standard treatment, resulting in prolonged illness, higher health care expenditures and a greater risk of death. Resistant bacteria strains may develop almost anywhere particularly in a pressurized environment containing previously non-resistant bacteria strains as contaminants. One of such environments can be an HMP. The HMPs have been previously implicated as a pool for such contaminations (Peter, 1999; Esimone et al., 2007). It is of utmost importance to both monitor and ascertain the microbial purity of these products given the huge medical and economic implications of any such microbial contamination especially with multiple drugresistant strains. Oleghe et al. (2011) in their study on multi-drug-resistant bacteria isolates recovered from herbal medicinal preparations in a southern Nigerian reported similar results on multidrug resistant bacteria.

Antibiotic resistance is one of the world's most pressing public health problems (WHO, 2010). Almost every type of bacteria has become stronger and less responsive to antibiotic treatment when it is really needed. Antibiotic resistance is recognized as a growing problem that poses a major threat to the continued effectiveness of antibiotics used to treat human and veterinary illnesses. Further exacerbating the problem, pharmaceutical companies are 
developing fewer new antibiotics to replace those that are no longer effective (Silbergeld et al., 2008). Furthermore these antibiotic-resistant bacteria can quickly spread to family members, schoolmates and co-workers threatening the community with a new strain of infectious disease that is more difficult to cure and more expensive to treat. Antibiotic resistance can cause significant danger and suffering for children and adults who have common infections. When a microbe becomes resistant to many drugs, treating the infections it causes can become difficult or even impossible and the illness can lead to serious disability, morbidity and mortality. Of great concern were the presence of pathogenic S. sonnei, E. coli and $K$. Pneumonia that were resistant to more than one antibiotic tested.

\section{Conclusion}

The herbal products were highly contaminated (90\%) and only $16 \%$ complied with the microbial limits specifications of Pharmacopoeias and WHO. The presence of antibiotic resistant strains of bacteria was evident and it is of great concern because the products are dispensed to the already sick population. The isolation of disease causing bacteria such as Shigella sonnei and E. coli is a major health risk to the general population. Hence, there is need for increased community education on these potential hazards. Also, there is need for policy development in Kenya that will guide on quality control measures and safe handling practices so as to reduce the health risks associated with microbial contamination. It is also recommended that genetic characterization of the isolated pathogenic strains that were resistant to more than one antibiotic should be carried out.

\section{Acknowledgement}

We sincerely acknowledge the Director KEMRI for providing an enabling environment for this work to be done. The authors are very grateful to Kenya National Commission for Science, Technology and Innovation (NACOSTI) for funding this work (NCST/RCD/ST\&I/WS/3rd CALL/104).

\section{Author's Contributions}

All authors equally contributed in this work.

\section{Declaration}

This article contains original research work and has not been published in any journal. All the authors have read and approved the manuscript. There are no ethical issues involved.

\section{References}

Abba, D., H. Inabo, S. Yakubu and O. Olonitola, 2008. Contamination of herbal medicinal products marketed in Kaduna metropolis with selected pathogenic bacteria. African J. Traditional, Complementary Alternative Med., 6: 70-77.

Alwakeel, S.S., 2008. Microbial and heavy metals contamination of herbal medicines. Res. J. Microbiol., 3: 683-691.

Angulo, F., V. Nargund and T. Chiller, 2004. Evidence of an association between use of anti-microbial agents in food animals and anti-microbial resistance among bacteria isolated from humans and the human health consequences of such resistance. J. Vet. Med. B, 51: 374-379. DOI: 10.1111/j.1439-0450.2004.00789.x

Barnes, J., 2003. Pharmacovigilance of herbal medicines: A UK perspective. Drug Safety, 26: 829-851. DOI: 10.2165/00002018-200326120-00001

Candlish, A., S. Pearson, K. Aidoo, J. Smith and B. Kelly et al., 2001. A survey of ethnic foods for microbial quality and aflatoxin content. Food Additives Contaminants, 18: 129-136. DOI: $10.1080 / 02652030010021404$

Czech, E., W. Kneifel and B. Kopp, 2001. Microbiological status of commercially available medicinal herbal drugs- A screening study. Planta Med., 67: 263-269. DOI: 10.1055/s-2001-12007

Deshpande, A., C. Kulkarni, A. Mane and G. Khairnar, 2010. Evaluation of microbiological quality of marketed herbal oral medicinal powders. J. Microbial. World, 12: 198-201.

DeWaal, C., J. Smith and S. Vaughn 2013. Antibiotic resistance in foodborne pathogens. Centre for Science in the Public Interest: The non-profit publishers of Nutrition Action Health letter. 1220 L Street N.W., Suite 300 Washington, DC.

Ernst, E., 1999. Complementary medicine-is it effective and safe? Drug Inf. J., 33: 291-295. DOI: $10.1177 / 009286159903300133$

Esimone, C.O., P.O. Oleghe, E.C. Ibezim, C.O. Okeh and I.R. Iroha, 2007. Susceptibility-resistance profile of micro-organisms isolated from herbal medicine products sold in Nigeria. African J. Biotechnol., 6: 2766-2775.

EP, 2007. Sixth Edition Strasbourg: European Council of Pharmacopoeia.

Farkas, J., 2000. Spices and Herbs. In: The Microbiological Safety and Quality of Food Gaithersburg, Lund, B.M., T.C. Baird-Parker and G.W. Gould (Eds.), Aspen Publishers; pp: 897-918.

Fisher, A.A., J.E. Laing and J.E. Strocker, 1998. Handbook for Family Planning, Operation Research Design in Sampling. 1st Edn., Population Council.

Forest, J., 2004. Faecal coliforms. University of Iowa Hygienic Laboratory Manual., 36: 2-4. 
Frazier, W. and D. Westhoff, 2003. Food Microbiology. 4th Edn., McGraw-Hill Publishing Company Limited.

Govender, S., D. Du Plessis-Stoman, T. Downing and M. Van de Venter, 2006. Traditional herbal medicines: Microbial contamination, consumer safety and the need for standards. South African J. Sci., 102: 253-255.

Harnack, J., S. Rydell and J. Stang, 2001. Prevalence of use of herbal products by adults in Minneapolis/St Paul, Minn, Metropolitan Area Mayo. Clin. Proc., 76: 688-694. DOI: 10.4065/76.7.688

Kaume, L., J.C. Foote, E. Edward and E.E. Gbur, 2012. Microbial contamination of herbs marketed to HIVinfected people in Nairobi, Kenya. South African J. Sci., 108: 9-10. DOI: 10.4102/sajs.v108i9/10.563

KHSP, 2010. World health organization global health observatory. Kenya Health Statistics Profile.

KNBS, 2009. Population and housing census highlights. Kenya National Bureau Statistics, Kenya.

Kirby, J., A. Bauer, W. Sherris and M. Turck, 1966. Antibiotic susceptibility testing by a standardized single disk method. Am. J. Clin. Pathol., 36: 493-496.

Kunle, O.F., H.O. Egharevba and P.O. Ahmadu, 2012. Standardization of herbal medicines: A review. Int. J. Biodiversity Conservation, 4: 101-112.

Langlois-Klassen, D., W. Kipp, G. Jhangri and T. Rubaale, 2007. Use of traditional herbal medicine by AIDS patients in Kabarole District, Western Uganda. Am. J. Tropical Med. Hygiene, 77: 757-763.

Lau, A., M. Holmes, S. Woo and H. Koh, 2003. Analysis of adulterants in a traditional herbal medicinal product using liquid chromatography mass spectroscopy. J. Pharmaceutical Biomedical Analysis, 31: 401-406. DOI: 10.1016/S0731-7085(02)00637-4

Liu, J., E. Manheimer and M. Yang, 2005. Herbal medicines for treating HIV infection and AIDS. Cochrane Database Systematic Rev., 2: 1-23. DOI: 10.1002/14651858.CD003937.pub2

Nakajima, K., K. Nonaka, K. Yamamoto, N. Yamaguchi and K. Tani et al., 2005. Rapid monitoring of microbial contamination on herbal medicines by fluorescent staining method. Lett. Applied Microbiol., 40: 128-132. DOI: 10.1111/j.1472-765X.2004.01643.x

NLSI, 2006. 940 West Valley Road, Suite 1400, Wayne, Pennsylvania 19087-1898 USA (Formerly National Committee on Clinical Laboratory Standards (NCCLS). National Laboratory Standards Institute.
Okunlola, A., A. Adewoyin and A. Odeku, 2007. Evaluation of pharmaceutical and microbial qualities of some herbal medicinal products in south western Nigeria. Tropical J. Pharmaceutical Res., 6: 661-670. DOI: 10.4314/tjpr.v6i1.14644

Oleghe, P.O., D.C. Odimegwu, E. Udofia and C.O. Esimone, 2011. Multi-drug-resistant bacteria isolates recovered from herbal medicinal preparations in a southern Nigerian setting. J. Rural Tropical Public Health, 10: 70-75.

Patwardhan, B., D. Warude, P. Pushpangadan and B.N. Narendra, 2005. Ayurveda and traditional chinese medicine: A comparative overview. Evidence-Based Complementary Alternative Med., 2: 465-473. DOI: 10.1093/ecam/neh140

Peter, A.G.M., 1999. Overview of herbal quality control. Drug Inform. J., 33: 717-724.

Rugut, E., R. Muasya and L. Gohole, 2010. Longevity of bean (Phaseolus vulgaris) seeds stored at locations varying in temperature and relative humidity. Int. J. Pure Applied Sci. Technol., 5: 60-70.

Shukla, S., M. Stemper, S. Ramaswamy, J. Conradt and R. Reich et al., 2004. Molecular characteristics of nosocomial and Native American community associated methicillin resistant Staphylococcus aureus clones from rural Wisconsin. J. Clin. Microbiol., 42: 3752-3757. DOI: 10.1128/JCM.42.8.3752-3757.2004

Silbergeld, E., L. Price and J. Graham, 2008. Antimicrobial resistance and human health. Pew Commission Industrial Farm Animal Production.

UNAIDS and WHO, 2009. (United Nations Programme on HIV/AIDS (UNAIDS) and World Health Organization (WHO) AIDS epidemic update towards universal access): Scaling up priority HIV/AIDS interventions in the health sector. Progress report; UNAIDS/09.36E/JC1700E Geneva

USP, 2005. Rockville: United states pharmacopoeia convention. United States Pharmacopeia.

WHO, 2010. Antimicrobial resistance. WHO.

WHO, 2007. Guidelines for assessing quality of herbal medicines with reference to contaminants and residues. WHO Press.

Wylie, J. and D. Nowicki, 2005. Molecular epidemiology of community-and health careassociated methicillin resistant Staphylococcus aureus in Manitoba, Canada. J. Clin. Microbiol., 43: 2830-2836. 